\title{
Effect of maternal dietary supplementation with Brazil nut (Bertholletia excelsa) on the nutritional profile of human milk: randomized controlled trial - rationale, design, and methods
}

Denise Rodrigues ( $\nabla$ denise.rodrigues@ufv.br)

Universidade Federal de Vicosa https://orcid.org/0000-0003-0359-9701

Roberta Sena Reis

Universidade Federal de Goias Faculdade de Nutricao

Kely de Paula Correa

Universidade Federal de Vicosa

Sylvia do Carmo Castro Franceschini

Universidade Federal de Vicosa

Jane Selia dos Reis Coimbra

Universidade Federal de Vicosa

Study protocol

Keywords: Human milk, Brazil nuts, supplementation

Posted Date: May 17th, 2020

DOI: https://doi.org/10.21203/rs.3.rs-27761/v1

License: (c) (i) This work is licensed under a Creative Commons Attribution 4.0 International License.

Read Full License 


\title{
STUDY PROTOCOL
}

EFFECT OF MATERNAL DIETARY SUPPLEMENTATION WITH BRAZIL NUT (BERTHOLLETIA EXCELSA) ON THE NUTRITIONAL PROFILE OF HUMAN MILK: RANDOMIZED CONTROLLED TRIAL - RATIONALE, DESIGN, AND METHODS

Denise Cristina Rodrigues ${ }^{1,2 *}$, Roberta Sena Reis ${ }^{3}$, Kely de Paula Correa ${ }^{1}$, Sylvia do Carmo Castro Franceschini ${ }^{4}$, Jane Sélia dos Reis Coimbra ${ }^{1}$

*Correspondence: Denise Cristina Rodrigues, denise.rodrigues@ufv.br

${ }^{1}$ Department of Food Technology, Universidade Federal de Viçosa, Viçosa, Minas Gerais, Brazil. ${ }^{2}$ Department of Medicine and Nursing, Universidade Federal de Viçosa, Viçosa, Minas Gerais, Brazil

\begin{abstract}
Background: The human milk (HM) composition reflects the nutritional status and dietary intake of the nursing mother, especially regarding the fatty acids (FA) intakes. Evidence has shown that Brazil nut is a good source of FA (mono and polyunsaturated) and selenium. Therefore, this study describes the design and methods of the Randomized Clinical Trial (RCT): "Effect of maternal dietary supplementation with Brazil nut (Bertholletia excelsa) on the nutritional profile of HM". Thus, this work reports the protocol that was used to evaluate the hypothesis that the consumption of Brazil nut during lactation can modify the nutritional profile of HM, increase its energy density, selenium content, and improve the lipid profile.
\end{abstract}


Method/Design: The present protocol was used to conduct a crossover study with mother-infant dyads (with infants born at full-term) recruited from a maternity hospital and followed up to the third month postpartum in a pediatric office. After verifying the eligibility criteria, the nursing mothers were invited to participate in the study and signed the informed consent form. Data collection was carried out by ensuring the confidentiality of personal information. Sociodemographic, lifestyle, obstetric, and birth data were collected at seven days postpartum. Maternal nutrition assessment data (anthropometry, body composition, food intake, biochemical tests), HM samples, and infant anthropometric and health assessment data were collected on average at 37, 52, 75, and 90 days postpartum. The nursing mothers were randomly allocated into two groups: group (1) started with supplementation of $1.5 \mathrm{~g} /$ day Brazil nut (case) for 15 days, followed by 15-day washout period; after the washout, the group was then considered as control and received follow-up monitoring for another 15 days; group (2) started as the control for 15 days, which was followed by a washout period of 15 days, then they initiated supplementation with Brazil nut for 15 days (case).

Discussion: To the best of our knowledge, this is the first proposal of a protocol to conduct a Randomized Clinical Trial (RCT) to evaluate the effect of maternal Brazil nut supplementation on HM nutritional profile.

Conclusion: This promising research area can provide findings that will contribute to improving the health and nutrition of infants, especially premature infants, admitted to Neonatal Intensive Care Units.

Keywords: Human milk, Brazil nuts, supplementation. 
Trial registration: RBR-54qqz5. Registered on March 28, 2019; www.ensaiosclinicos.gov.br.

\section{Introduction / Background}

Human milk (HM) contains bioactive compounds that are responsible for better immune response, especially in preterm newborns (NB), besides providing the necessary nutrients for proper growth and development1. Some clinical or surgical circumstances prevent newborns from sucking their mothers' breasts; thus, Neonatal Intensive Care Units (NICU) have encouraged feeding with milk pumped from their mothers or a human milk bank. (HMB) [1, 2]. Human milk feeding has been shown to reduce the incidence of necrotizing enterocolitis, which is the most acute morbidity of preterm infants, as well as neonatal sepsis [3-7].

One should also consider that the HM composition is influenced by the nutritional status and dietary intake of the nursing mother $[8,9]$, especially the intake of fatty acids (FA) such as alpha-linolenic acid (omega 3) and linoleic acid (omega 6), which are essential in the diet $[8,10]$. The role of these FAs in the development of NBs is well recognized, especially preterm infants, who are in a highly vulnerable phase $[9,11]$.

Besides, variability in HM composition at different postnatal periods may require the application of specific strategies to optimize the nutrient supply to NB, particularly preterm infants [12]. Maternal supplementation studies have been conducted to improve HM energy intake and lipid profile [13-16]. Studies conducted in countries in Europe, the United States, and Brazil have supplemented nursing mothers with docosahexaenoic AG (DHA) capsules [13, 15, 17], eicosapentaenoic AG (EPA) capsules in addition to DHA 
[16, 18], rapeseed oil, and omega 3 enriched margarine [14], sardine consumption [19], and diets with different levels of arachidonic acid [18].

Evidence has shown that the Brazil nut (a native food) is a good source of FA (mono and polyunsaturated) and selenium [20, 21]. Therefore, this study presents a protocol to evaluate the hypothesis that ingesting Brazil nut during lactation can modify the nutritional profile of HM, increase its energy density and selenium content, and improve its lipid composition. To our knowledge, this is the first proposal to carry out a randomized controlled trial $(\mathrm{RCT})$ that evaluates the effect of maternal Brazil nut supplementation on the nutritional profile of human milk. This is a promising research area that can provide findings that will contribute to improving the health and nutrition of newborns, especially premature newborns, admitted to Neonatal Intensive Care Units (NICU). Therefore, this work describes the design and methods of the RCT titled "Effect of maternal dietary supplementation with Brazil nut (Bertholletia excelsa) on the nutritional profile of human milk."

\section{Methods / Design}

The present proposal of the crossover study aimed (1) to investigate the effect of maternal dietary supplementation with Brazil nut (Bertholletia excelsa) on the nutritional HM profile; (2) to characterize the nutritional profile of the Brazil nut; (3) to evaluate the macronutrient composition and the selenium content of LH; (4) to evaluate the effect of the supplementation on the nutritional status, body composition, and biochemical markers of nursing mothers; and (5) to investigate alterations in the HM nutritional composition and its effect on infant growth.

\section{Participants}


Nursing mothers and their infants, full-term (37 to 42 weeks), were recruited at São Sebastião Hospital (HSS) in Viçosa, Minas Gerais, Brazil. HSS is a reference for maternal and child care and is the only hospital in the region that has a human milk bank (HMB). The HMB-HSS was registered at the Brazilian HMB Network of the Brazilian Ministry of Health, in 2011. A total of 365 women donated 439.2 L of HM in 2018. Part of this milk (284.2 L) was allocated to the NICU, feeding 179 preterm infants. Also, 885 deliveries (monthly average of 74 deliveries) were performed at the HSS, of which $8.2 \%$ were premature, according to the Live Birth Information System (SINASC)/Viçosa-MG Municipal Health Department.

The inclusion criteria for the participation in this study were: all mothers and infants live in Viçosa; healthy full-term infants with adequate weight for gestational age; exclusive breastfeeding; nursing mothers willing to donate breastmilk samples to research; mothers' age between 18 and 40 years; delivery performed using the Unified Health System (SUS); and mothers agreeing to participate and signing the informed consent form. The non-inclusion criteria were: nursing mothers who had regular consumption of Brazil nuts, mothers who had a nut allergy, mothers who had diseases in the current pregnancy. The exclusion criteria were: interruption of exclusive breastfeeding during the study period without medical recommendation; non-attendance at scheduled meetings; interruption of HM sample collection, or development of allergy or intolerance to Brazil nuts at any time.

\section{General information}

Nursing mothers and infants were recruited at the HSS and followed up in the pediatric office by the researchers (pediatrician and nutritionist) up to the third month 
after delivery. During the study, two telephone numbers of contact persons were provided to participants for clarification.

Research data collection was performed in 7 phases (Figure 1):

1. Recruitment (maternity): it was carried out at the HSS hospital. The researchers contacted the mothers in the maternity ward within the first $48 \mathrm{~h}$ after delivery. At this time, the research was presented to the mothers, and they were invited to participate in the study. If there was interest, an appointment was made with the researchers at the pediatric office.

2. The first phase (first appointment - 7 days postpartum, on average): it was performed at the office. On this day, the informed consent form was presented and signed; the nursing mother was interviewed and instructed to complete the 3-day food record, which should be handled at the next meeting. The baby's first appointment was held, providing a thorough physical examination and guidance on breastfeeding and healthy eating for the mothers. The guideline folders were handled.

3. The second phase (home visit): it took place at the participants' homes. At this meeting, the researchers provided the guidelines on the collection and storage of HM. Folders containing information based on texts written by the team at the HMB-HSS in Viçosa were offered to mothers. The interviews were stored on a laptop from the Ministry of Health [22]. Breastmilk home collection was requested within 3 days before the next appointment. The researchers provided a collection kit with 3 sterile bottles, 3 caps, and 3 masks. Besides, the nursing mothers were guided on the bioimpedance analysis and biochemical exams to be performed at the next meeting. The researchers fetched the milk samples and the food records at the participant's home on the day before the appointment. This procedure was done to ensure the storage, refrigeration, and transportation of HM following the rules of the Brazilian HMB Network [23]. 
4. The third phase (second appointment - 37 days postpartum, on average): it was held at the pediatrician office. At this appointment, the mother's nutritional assessment and biochemical exams were performed, as well as the baby's physical examination. A drawing was held to determine whether the nursing mother would start the study as a case or as control. Thus, the nursing mothers were randomly allocated into two groups by simple drawing: group (1) started with supplementation of $1.5 \mathrm{~g} /$ day Brazil nut (case) for 15 subsequent days, followed by 15 days of washout; after the washout, the group was then considered as control and received follow-up monitoring for another 15 days; group (2) started as the control for 15 days, which was followed by a washout period of 15 days, then they started the supplementation with Brazil nut for 15 days (case). All nursing mothers (case or control) were requested to provide the 3-day food record and the collection of breastmilk at home within 3 days before the next meeting. As in the second phase, the researchers fetched the breastmilk samples, and the food records the day before the appointment at the participants' homes. The next meeting was scheduled for 15 days later.

5. The fourth phase (third appointment - 52 days postpartum, on average): it was held at the pediatrician office. At this appointment, the mother's nutritional assessment and biochemical exams were performed, as well as the baby's physical examination. The next appointment was scheduled for 15 days later. At this time, the nursing mothers went through a washout period.

6. The fifth phase (fourth appointment): it was held at the pediatrician office. All nursing mothers (case or control) were requested to provide the 3-day food record and the collection of breastmilk at home within 3 days before the next meeting. As in the second phase, the researchers fetched the breastmilk samples, and the food records the day before 
the appointment at the participants' homes. The next meeting was scheduled for 8 days later.

7. The sixth phase (fifth appointment - 75 days postpartum, on average): it was held at the pediatrician office. At this appointment, the mother's nutritional assessment and biochemical exams were performed, as well as the baby's physical examination. At this time, portions of Brazil nuts were provided to the nursing mothers who started the study as control, which were ingested for 15 subsequent days. The nursing mothers who started the study with nut supplementation moved to the control group, i.e., without supplementation. All nursing mothers (case or control) were requested to provide the 3 day food record and the collection of breastmilk at home within 3 days before the next meeting. As in the second phase, the researchers fetched the breastmilk samples, and the food records the day before the appointment at the participants' homes. The next meeting was scheduled for 15 days later.

8. Seventh phase (sixth appointment - 90 days postpartum, on average): it was held at the pediatrician office. At this appointment, the mother's nutritional assessment and biochemical exams were performed, as well as the baby's physical examination. After that, monthly appointments were scheduled for babies until the sixth month and then at 9 and 12 months of age.

A pilot study was conducted before data collection with the objectives of assessing recruitment dynamics, testing the data collection tool, and evaluating the average duration of questionnaires and the feasibility of breastmilk collection by participants at their homes. The investigators responsible for the collection, biochemical analysis, and physicochemical analysis of the breastmilk were blinded.

Figure 1. Recruitment and data collection flowchart. 


\section{Study Variables}

Information regarding the recruitment of participants was obtained through a semi-structured tool designed by the researchers, which contained variables that were collected from: (1) HSS birth registry: date, type of delivery, weight, and length at birth, sex, gestational age, maternal age, health insurance or SUS, city. The baby was classified according to birth weight by gestational age [24], considering adequate for gestational age the newborn who is between the $10^{\text {th }}$ and $90^{\text {th }}$ percentiles in the growth curve weight/gestational age; (2) pregnant woman's handbook (hospital ward): previous pathological history, maternal and gestational age assessment; (3) interviewing the mothers (maternity) about regular consumption of Brazil nuts, allergy to Brazil nuts, health problem or use of medication during pregnancy, type of breastfeeding, willingness to donate milk to research if assisted by a pediatrician.

Information regarding the follow-up monitoring (first to the seventh phase) of the participants was obtained through a semi-structured protocol designed by the researchers, which was composed by variables: (1) Maternal sociodemographic characteristics: residence; age; schooling; profession; marital status; total household income (in Brazilian reals and minimum wages); number of people dependent on income; (2) Nutrition and lifestyle assessment of the nursing mothers: food consumption; anthropometry; body composition; lifestyle habits (alcohol consumption and smoking); physical activity; biochemical exams; (3) Maternal obstetric history: pre-gestational weight; pre-gestational body mass index (BMI); pre-gestational BMI classification; weight gain during pregnancy; weight at the end of pregnancy; weight gain classification; number of appointments during prenatal care; gestational complications; gestational age; use of medication and supplements during pregnancy; obstetric history (number of gestation, breastfeeding); type of delivery; (4) Child nutritional assessment: sex; date of birth; 
weight; length; BMI; cephalic, thoracic, and abdominal perimeters; (5) Analysis of Brazil nuts; (6) HM analysis.

\section{Outcome measures}

The proposed primary and secondary outcome measures are shown in Table 1.

\section{Data collection tools according to 5 domains}

Nutrition (Assessment of food intake)

The dietary intake of the nursing mothers was evaluated by the 3-day nonconsecutive dietary record (two weekdays and one weekend day). The nursing mothers received a structured guideline and detailed instructions on how to complete it. The 3-day food record was collected and evaluated in four follow-up appointments (second, third, fifth, and sixth appointments) (3 food records per appointment, totaling 12 food records in the research). The software application used to analyze the food records was AVANUTRI®. It was calculated the total energy value, carbohydrates, proteins, lipids (polyunsaturated, saturated AG, cholesterol), fiber, vitamins $\mathrm{A}, \mathrm{D}, \mathrm{E}$, and $\mathrm{K}$, zinc, and selenium. The following tables were used for the analysis of the chemical composition of the mothers' diet: Brazilian Food Composition Table [25], Food Composition Table [26[; Table for Assessment of Food Consumption by Household Measures [27]; Table of Equivalents, Household Measures, and Chemical Composition of Foods [28]; TBCA-USP [29], as well as information described on processed food labels. Diet was adjusted for macro and micronutrients by calculating the average intake of the three-day food record and adjusted for intraindividual variability as well as dietary energy density (Total Energy Value) [30]. 


\section{Anthropometry of Nursing Mothers and Infants}

The anthropometric evaluation of the nursing mothers was performed, and weight and height were measured. Weight was measured on a digital electronic scale (Marte®PP 180, São Paulo, Brazil), with 199.95 kg capacity and 50 g accuracy. Women were in the orthostatic position, with arms hanging at sides and looking straight ahead [31]. Height was measured using a portable stadiometer (Alturexata ${ }^{\circledR}$, Belo Horizonte, Brazil), with a measuring range of $2130 \mathrm{~mm}$ and graduation of $1 \mathrm{~mm}$, mounted on a metal platform for positioning the subjects and a dismantling wooden measuring rod with a scale printed along the side and a sliding headpiece. For the measurements, the women were barefoot and wore light clothing, were stood against the wall, and looking forward with their feet joined [31]. The nutritional status of the nursing mothers was assessed by Body Mass Index (BMI) by dividing the weight $(\mathrm{kg})$ by the squared height $\left(\mathrm{m}^{2}\right)$. The cutoff points to assess nutritional status were proposed by the World Health Organization (1998) [32]. Pre-gestational BMI and weight gain during pregnancy were assessed as proposed by the Institute of Medicine (2009) [33].

The body composition of the nursing mothers was evaluated by tetrapolar horizontal bioimpedance using Biodynamics $310 \mathrm{e}{ }^{\circledR}$ electrodes, following the manufacturer's recommendations. According to the protocol, the participants were instructed to suspend the use of diuretic drugs at 7 days before the test; to avoid the consumption of alcohol in the last $48 \mathrm{~h}$.; to abstain from intense physical activity in the last $24 \mathrm{~h}$; and, not to wear any metal accessories or equipment while having the test [34]. The test was performed between 7:30 am and 11:00 am. The adult cutoff points proposed by Lohman (1992) were used to classify the body fat percentage [35].

The anthropometric assessment of the infants was performed by measuring weight and length, and the head, thoracic and waist circumferences. The weights of the babies 
were measured using a pediatric electronic scale (Welmy®, Santa Barbara d'Oeste, Brazil), with $15 \mathrm{~kg}$ capacity and $5 \mathrm{~g}$ sensitivity, with the children naked. The length of the infants was measured using a portable stadiometer with measuring range of $121.5 \mathrm{~cm}$ and graduation of $0.1 \mathrm{~cm}$, consisting of a portable headpiece adapter coupled to a dismantling wooden measuring rod with a scale printed along the side and a sliding headpiece for reading (Alturexata ${ }^{\circledR}$, Belo Horizonte, Brazil). One of the investigators (or the person who accompanied them) held the child's head with both hands, supporting the baby horizontally and keeping in contact with the anthropometric ruler. The other researcher pressed the baby's knees toward the surface so that legs were extended and moved the sliding headpiece with his other hand until it touched the two soles of the feet $[31,36]$. Head circumference was measured with a flexible, non-stretchable measuring tape positioned horizontally around the child's head, with the frontal occipital circumference corresponding to the maximum head circumference (most prominent part on the back of the head) [36]. Thoracic circumference was measured with a flexible, nonstretchable measuring tape positioned around the chest. Waist circumference was measured with a flexible, non-stretchable measuring tape positioned above the umbilical scar.

The nutritional status of infants was assessed according to sex by the anthropometric indices weight for age (WFA), length for age (LFA), weight for length (WFL), and body mass index for age (BMIFA). Anthropometric references by WHO were adopted for children below 5 years of age (WHO, 2006) [37]. The index was obtained by calculating the z-score using the software WHO Anthro (WHO, 2009) [38]. The nutritional status diagnosis was according to WHO Z-score recommendation [39].

\section{Biochemical Assessment}


In the nursing mothers, blood samples of $15 \mathrm{~mL}$ were collected after $12 \mathrm{~h}$ of fasting and analyzed at the Laboratory of Clinical Analysis. Total cholesterol (TC) and high-density lipoprotein cholesterol (HDL-c), low-density lipoprotein cholesterol (LDLc), very low-density lipoprotein cholesterol (VLDL-c), triglycerides, complete blood count, fasting glucose, TSH, free T4, and selenium were measured [40-46]. Table 2 presents the methodologies and equipment/companies used for measuring the parameters studied. All persons related to the biochemical analyses were blinded. All persons associated with the biochemical analyses were blinded.

\section{Biological Assessment (HM collection and physicochemical analysis)}

Collection of HM samples was carried out by the nursing mothers themselves, by hand expression, between 8:00 and 11:00 am, on three consecutive days and before four following up appointments (the first, third, fifth, and sixth appointments). The expression was determined on the left breast, and the nursing mothers were instructed to discard the first $5 \mathrm{~mL}$ of milk before collecting the sample. After each collection, the capped bottles were stored correctly in a freezer at home, and later transported to the Department of Food Technology of the Federal University of Viçosa (UFV), where they were stored in a freezer $\left(-20^{\circ} \mathrm{C}\right)$ and further pasteurized $\left(62.5^{\circ} \mathrm{C} / 30\right.$ minutes $)$. After pasteurization, the samples were separated into $10 \mathrm{~mL}$ aliquots for analysis of selenium, FA, and lactose; 30 $\mathrm{mL}$ aliquot for acidity and $\mathrm{pH}$; and $80 \mathrm{~mL}$ aliquot for fat, crematocrit, ashes, dry extract, and protein.

HM physical-chemical analysis, including $\mathrm{pH}$, titratable acidity, fixed mineral residue, total dry extract, lactose, protein, and fat, used the methodology described by the Association of Official Agricultural Chemists (AOAC) [45]. Also, FA was determined 
according to the Adolf Lutz Institute [46]. All persons who participated in the physicalchemical analysis of milk were blinded.

Acidity was determined by the stoichiometric reaction between the standard alkaline titrant sodium hydroxide and the acidic constituents present in HM. Acidity greater than or equal to $8^{\circ} \mathrm{D}$ disqualifies the product for consumption according to AOAC [45]. Analysis of fixed mineral residue and total dry extract followed the methodology proposed by AOAC [45]. Lactose quantification was determined by ion-exchange chromatography, using a chromatograph equipped with an auto-injector (Metrohm®, 919 IC, Switzerland), an amperometric pulse detector (Metrohm® ${ }^{\circledR}, 896$, Switzerland), and the software MagiC Net 2.4®.

Protein was measured using the Bradford assay [47]. The principle of this essay is based on the addition of ethanol, phosphoric acid, and the dye Coomassie Brilliant Blue G-250 to the protein-containing solution. Under acidic conditions, the dye interacts with the high molecular weight protein and shift from anionic (red) to cationic (blue) form, which absorbs strongly at $595 \mathrm{~nm}$. The complex is rapidly formed (2 minutes), remains dispersed in the solution for a relatively long time, one hour, and has a high extinction coefficient, which allows for high sensitivity protein quantification.

The protein standard curve was constructed using bovine serum albumin (10 -100 $\mu \mathrm{g}$ albumin in $100 \mu \mathrm{L}$ solution). The linear equation was obtained according to absorbance data.

The creamatocrit and the Gerber method measured fat content. According to the Brazilian HMB Network [48], creamatocrit is an "analytical technique for determining cream content, which allows the calculation of fat content and energy content of the expressed HM" [49]. The expressed HM was mixed well in a bottle. Then, 3 aliquots of $75 \mu \mathrm{L}$ were collected and filled into capillary tubes, centrifuged for 15 minutes, then the 
height of the packed material in the capillary tube was measured. Two columns were measured: the upper part of the capillary tube holds the cream column, and the bottom holds the serum column. The column measures were fed into the formulas for cream and fat contents: $(1) \%$ Cream $=$ Cream content $-100 \cdot$ Cream column $(\mathrm{mm}) /$ Total column $(\mathrm{mm}) ;(2) \%$ Fat $=$ Fat content $-(\%$ Cream -0.59$) / 1.46 ;(3)$ Energy content $(\mathrm{kcal} / \mathrm{L})=$ Total energy content $-\%$ cream $\cdot 66.8+290$. The Gerber method is based on the digestion of organic matter by sulfuric acid, except for the fat that will be separated by centrifugation, and the addition of isoamyl alcohol that modifies surface tension. In this method, $11 \mathrm{~mL}$ of well-mixed $\mathrm{HM}$ was added to a butyrometer containing $10 \mathrm{~mL}$ of the $\mathrm{d}=1.825$ sulfuric acid solution at $20{ }^{\circ} \mathrm{C}$, slowly to avoid mixing with the acid, and $1 \mathrm{~mL}$ of isoamyl alcohol was added to facilitate separation. The butyrometer was stoppered, and the contents were mixed to complete the homogenization of liquids. The mixture was centrifuged for 5 minutes, from 1000 to $1200 \mathrm{rpm}$, and kept in a water bath at $65{ }^{\circ} \mathrm{C}$ for 5 minutes to facilitate viewing. The reading was performed on the butyrometer scale divisions (Rule 68/2006) [50].

FA was measured by lipid extraction according to the methodology described by the Adolf Lutz Institute [46]. The samples for FA characterization were prepared by the direct transesterification method adapted from the methodology described by Martinez et al. [51]. FA determination was performed by gas chromatography (GC-2010®, Shimadzu Corporation, Kyoto, Japan).

\section{Brazil nut consumption and laboratory analysis}

Brazil nut consumption was calculated considering the intake between the Dietary Reference Intake (DRI) of $70 \mu \mathrm{g} /$ day and the Tolerable Upper Intake Level (UL) of 400 $\mu \mathrm{g} /$ day for nursing mothers [52]. The nursing mothers received $1.5 \mathrm{~g} / \mathrm{day}$ of this food. 
The analysis of the centesimal composition of Brazil nuts (carbohydrates, fat, and total protein) was carried out in a Clinical Analysis Laboratory using the methodology described by the Adolfo Lutz Institute [46] in a random sample of Brazil nuts purchased from the same supplier from Belém-PA. Selenium and fiber were measured using AOAC methodology [45]. The chemical analysis was performed in 3 parts of the research before starting, in the middle, and near the end. The average values of the three analyses were used for the chemical composition of Brazil nuts. Also, at these three times, random samples of Brazil nuts were microbiologically analyzed to ensure consumption.

Microbiological analyses to determine mesophilic bacteria, fungi, and yeasts used the method of counting microorganism colonies on plates (CFU/g). Total coliforms at 35 ${ }^{\circ} \mathrm{C}$ and coliforms at $45{ }^{\circ} \mathrm{C}$ (thermotolerant) were determined by the Most Probable Number Method (MPN/g), according to tolerance parameters required by the RDC Resolution No. 12 of January 2, 2001 [53] and according to methodologies described by Vanderzant and Splittstoesser (1992) [54].

For the analyses, a mass of $25 \mathrm{~g}$ of the sample was separated, and decimal dilutions (10-1; 10-2; 10-3) were prepared using sterile saline solution. Standard Plate Count (SPC) of Mesophilic Bacteria (CFU/g) was carried out on Standard Counting Agar (SCA) incubated at $35{ }^{\circ} \mathrm{C}$ for $48 \mathrm{~h}$. Counting of fungi and yeast (CFU/g) was carried out on Potato Dextrose Agar (BDA) incubated at $25{ }^{\circ} \mathrm{C}$ for 5 days. The method used for these analyses (each dilution) was surface plating.

Total coliforms at $35{ }^{\circ} \mathrm{C}$ and thermotolerant coliforms at $45^{\circ} \mathrm{C}$ were determined by the multiple tube technique, with three sets of three tubes for each dilution $(10-1 ; 10-$ $2 ; 10-3)$. The lauryl sulfate tryptose broth used as the presumptive medium was incubated at $35{ }^{\circ} \mathrm{C}$ for $48 \mathrm{~h}$. After reading, the tubes with a positive reading, which showed gas production, were subcultured into Escherichia Coli (EC) broth and incubated at $45^{\circ} \mathrm{C}$ for 
$24 \mathrm{~h}$, for confirmation of thermotolerant coliforms. The determination of the Most Probable Number (MPN/g) of coliforms was performed using the Hoskins table.

Brazil nuts were weighed and stored in vacuum packages, sealed, protected from the sunlight, and given to each participant with the consumption guidelines.

\section{Sample Size}

In this study, we considered the study population of Fidler et al. [17], in which after two weeks of supplementation with DHA, the milk of the supplemented nursing mothers had mean DHA content of $0.37 \mathrm{wt} \%$ vs. $0.21 \mathrm{wt} \%$ (percentage by weight) of the control group with significant difference $(\mathrm{p}=0.003)$. The final minimum sample calculated was of 24 nursing mothers, with a $20 \%$ increase to cover follow-up losses, taking into consideration the difference between the groups of $0.16 \mathrm{wt} \%$, a significance level of $5 \%$, and power of the test of $80 \%$. Thus, the final sample was calculated as 30 mother-infant dyads.

The recruitment for the pilot study was carried out from 01/09/2018 to 07/09/2018. During this period, 39 women delivered, and 6 of them met the inclusion criteria and were invited to participate. Two of these 6 mothers refused: one already had a pediatrician to attend to their children, and the other resided in another city (she used a relative's address for registration at HSS). Of the 4 mothers invited, 3 attended the first appointment.

The recruitment for the main study was carried out from 10/15/2018 to 11/22/2018. In this period, 177 women delivered, and 44 met the inclusion criteria and were invited to participate. Three of these mothers refused for the same reason mentioned above: they already had a pediatrician to attend to their children. Of the 41 mothers invited, 31 attended the first appointment. A mother was indicated to participate in the 
research and voluntarily sought out the researcher. She met the inclusion criteria and was accepted in the study. There were 3 losses during the follow-up, resulting in the sample size of 28 mother-infant dyads (Figure 2).

Figure 2. Consort diagram of subjects selected, invited, and who completed the study.

\section{Data analysis}

Data was entered Microsoft Excel spreadsheet for tabulation and exported to Statistical Package for the Social Sciences (SPSS) version 23 for analysis. The normality of variable distribution was assessed using the Kolmogorov-Smirnov test. Data analysis consisted of (1) Description of variables of interest in which the continuous variables were presented as mean and standard deviation (normal distribution) and as median and minimum and maximum values (asymmetric distribution). Qualitative variables were presented as absolute and relative frequencies; (2) Differences between case (supplemented) and control (non-supplemented) groups for sociodemographic, gestational, maternal, anthropometric, and dietary variables at baseline were assessed by the t-test (variables with normal distribution) or Mann-Whitney test (non-symmetric), and the chi-square test for categorical variables. These tests were also applied to compare the percentage deltas between the independent groups for the HM components and the anthropometric, dietary, and body composition variables of the mother-infant dyad; (3) Modifications of milk components in each group (before $v s$. after) were compared using the paired t-test or Wilcoxon test for parametric or nonparametric variables, respectively (Figure 3); and (4) The effect of supplementation between the supplemented and control groups was evaluated by one-way ANOVA (Figure 3). The significance level of $\alpha=5 \%$ was used as the probability of rejecting the null hypothesis. 
Figure 3. HM analysis and biochemical tests flowchart.

\section{Discussion}

To our knowledge, this is the first RCT to evaluate the effect of maternal Brazil nut supplementation on the nutritional profile of HM. The supplement tested is expected to contribute to the increase of the caloric content and selenium and improve the HM lipid profile. As a result, the improved breastmilk will be used in neonatal ICUs, contributing to weight gain in premature infants, which may reduce the mortality of this group and enhance their neurological development. This is a promising research area that can provide findings that will contribute to improving the health and nutrition of infants, especially premature infants, admitted to Neonatal Intensive Care Units.

As retribution to the studied population, after the study completion, the children will be under the care of the researcher/pediatrician up to the age of one year. During this time, childcare consultations will be held as recommended by the Brazilian Society of Pediatrics [55].

\section{Declarations}

\section{Ethics approval and consent to participate}

The study was approved by the Human Research Ethics Committee of the Federal University of Viçosa, Minas Gerais, Brazil, using the opinion number 2.763.503 and was registered under the CAAE certificate number 78516017.0.0000.5153. It was published in the Brazilian Registry of Clinical Trials (ReBEC) with the number RBR-54qqz5 and also registered by the Ethics Committee of the São Sebastião Hospital, Viçosa, Brazil. After verifying the eligibility criteria, the nursing mothers with their children were invited 
to participate in the study and signed the informed consent form. Data collection was carried out by ensuring the confidentiality of personal information.

\section{Consent for publication}

Not applicable.

\section{Availability of data and materials}

Data sharing not applicable to this article as no datasets were generated or analyzed during the current study.

\section{Competing interests}

The authors declare that they have no competing interests.

\section{Funding}

This study was supported by $\mathrm{CNPq}$ (National Council for Scientific and Technological Development) and FAPEMIG (Minas Gerais State Research Support Foundation). There was no involvement of CNPq and FAPEMIG in the study design, analysis, or interpretation of results, or the writing of the manuscript.

\section{Authors' contributions}

DCR conceptualized, designed and analyzed the study protocol, and wrote the manuscript. RSR designed and analyzed the study protocol. KPC designed the study protocol. SCCF and JSRC supervised the whole study protocol since the conceptualization of the study to the finalization of the manuscript. All authors read and approved the final manuscript. All authors read and approved the final manuscript. 


\section{Acknowledgments}

We gratefully acknowledge all the mothers who agreed to take part in the research that was conducted using this study protocol for their time. Also, we are genuinely grateful to the staff of São Sebastião Hospital for their assistance with this study.

\section{Author information}

\section{Affiliations}

${ }^{1}$ Department of Food Technology, Universidade Federal de Viçosa, Viçosa, Minas Gerais, Brazil.

Denise Cristina Rodrigues, Kelly de Paula Correa, Jane Selia dos Reis Coimbra

${ }^{2}$ Department of Medicine and Nursing, Universidade Federal de Viçosa, Viçosa, Minas Gerais, Brazil

Denise Cristina Rodrigues

${ }^{3}$ Nutrition College, Universidade Federal de Goias, Goiania, Goias, Brazil.

Roberta Sena Reis

${ }^{4}$ Department of Nutrition and Health, Universidade Federal de Viçosa, Viçosa, Minas Gerais, Brazil.

Sylvia do Carmo Castro Franceschini

\section{Corresponding author}

Correspondence to Denise Cristina Rodrigues 


\section{References}

1. American Academy of Pediatrics. Breastfeeding and the Use of Human Milk. Pediatrics [Internet]. 2012 March 1;129(3):e827-41. Available from: http://pediatrics.aappublications.org/cgi/doi/10.1542/peds.2011-3552

2. Vieira AA, Moreira MEL, Rocha AD, Pimenta HP, Lucena SL. Análise do conteúdo energético do leite humano administrado a recém-nascidos de muito baixo peso ao nascimento. J Pediatr (Rio J). 2004;80(6):490-4.

3. Uauy R, Koletzko B. Defining the Nutritional Needs of Preterm Infants. In: Volume Editors, editor. Ann Nutr Metab [Internet]. 2014. p. 4-10. Available from: https://www.karger.com/Article/FullText/358453

4. Lessen R, Kavanagh K. Position of the academy of nutrition and dietetics: Promoting and supporting breastfeeding. J Acad Nutr Diet. 2015;115(3):444-9.

5. Rønnestad A, Abrahamsen TG, Medbø S, Reigstad H, Lossius K, Kaaresen PI, et al. LateOnset Septicemia in a Norwegian National Cohort of Extremely Premature Infants Receiving Very Early Full Human Milk Feeding. Pediatrics. 2005;115(3):e269-76.

6. J.Meinzen-Derr, Poindexter B, Wrage L, Morrow A, Stoll B, Donovan EF. Role of Human Milk in Extremely Low Birth Weight Infants' Risk of Necrotizing Enterocolitis or Death. 2009;29(1):57-62.

7. Cristofalo EA, Schanler RJ, Blanco CL, Sullivan S, Trawoeger R, Kiechl-Kohlendorfer U, et al. Randomized Trial of Exclusive Human Milk versus Preterm Formula Diets in Extremely Premature Infants. J Pediatr. 2013;163(6):1592-1595.e1.

8. Do Amaral YN V, Marano D, Da Silva LML, Guimarães ACLD, Moreira MEL. Are There Changes in the Fatty Acid Pro fi le of Breast Milk with Supplementation of Omega3 Sources? A Systematic Review. Rev Bras Ginecol e Obstet. 2017;39(3):128-41.

9. Segura SA, Ansótegui JA, Díaz-Gómez NM. The importance of maternal nutrition during 
breastfeeding: Do breastfeeding mothers need nutritional supplements? An Pediatría (English Ed. 2016;84(6):347.e1-347.e7.

10. Carlson SE. Docosahexaenoic acid supplementation in pregnancy and lactation. In: American Journal of Clinical Nutrition. 2009. p. 678S-84S.

11. Agostoni C. Role of long-chain polyunsaturated fatty acids in the first year of life. J Pediatr Gastroenterol Nutr. 2008;47:Suppl 2:S41-4.

12. Pizarro M, Mena P, Bodini A. Composición de leche materna en madres de recién nacidos de pre- termino menor a 33 semanas. Rev Pediatría Electrónica. 2015;12(2):2-13.

13. Sherry CL, Oliver JS, Marriage BJ. Prostaglandins, Leukotrienes and Essential Fatty Acids Docosahexaenoic acid supplementation in lactating women increases breast milk and plasma docosahexaenoic acid concentrations and alters infant omega $6: 3$ fatty acid ratio. Prostaglandins Leukot Essent Fat Acids [Internet]. 2015;95:63-9. Available from: http://dx.doi.org/10.1016/j.plefa.2015.01.005

14. Mazurier E, Rigourd V, Perez P, Buffin R, Couedelo L, Vaysse C, et al. Effects of Maternal Supplementation with Omega-3 Precursors on Human Milk Composition. J Hum Lact. 2017;33(2):319-28.

15. Valentine CJ, Morrow G, Pennell M, Morrow AL, Hodge A, Haban-Bartz A, et al. Randomized Controlled Trial of Docosahexaenoic Acid Supplementation in Midwestern U.S. Human Milk Donors. Breastfeed Med [Internet]. 2013 Feb;8(1):86-91. Available from: http://www.liebertpub.com/doi/10.1089/bfm.2011.0126

16. Much D, Brunner S, Vollhardt C, Schmid D, Sedlmeier E, Brüderl M, et al. Breast milk fatty acid profile in relation to infant growth and body composition : results from the INFAT study. Pediatr Res. 2013;74(2):230-7.

17. Fidler N, Sauerwald T, Pohl a, Demmelmair H, Koletzko B. Docosahexaenoic acid transfer into human milk after dietary supplementation: a randomized clinical trial. J Lipid 
Res. 2000;41(9):1376-83.

18. Weseler AR, Dirix CEH, Bruins MJ, Hornstra G. Dietary Arachidonic Acid DoseDependently Increases the Arachidonic Acid Concentration in Human Milk. J Nutr. 2008;138(11):2190-7.

19. Patin R V, Vitolo MR, Valverde MA, Carvalho PO, Pastore GM, Lopez FA. The influence of sardine consumption on the omega-3 fatty acid content of mature human milk. J Pediatr (Rio J). 2006;82(1):63-9.

20. Ariane MK, Maristela M, Silmara MM, Renata HS, Karine SN, Helyde AM, et al. Properties of Brazil nuts: A review. African J Biotechnol [Internet]. 2015 February 25;14(8):642-8. Available from: http://academicjournals.org/journal/AJB/articleabstract/A47325150684

21. Ryan E, Galvin K, O’Connor TP, Maguire AR, O’Brien NM. Fatty acid profile , tocopherol, squalene and phytosterol content of brazil, pecan, pine, pistachio and cashew nuts. Int J Food Sci Nutr. 2006;57(3/4):219-28.

22. Brasil. Ministério da Saúde. Secretaria de Atenção Básica. Departamento de Atenção Básica. Cadernos de Atenção Básica. Saúde da Criança. Aleitamento Materno e Alimentação Complementar [Internet]. 2. ed. Ministério da Saúde, editor. Brasília; 2015. $184 \mathrm{p}$. Available from: http://dab.saude.gov.br/portaldab/biblioteca.php?conteudo=publicacoes/cab23

23. Almeida JAG de, Guimarães V, Novak FR. Normas Técnicas RedeBLH-BR para Bancos de Leite Humano [Internet]. Rio de Janeiro: FIOCRUZ/IFF- BLH; 2005. 44 p. Available from: http://www.redeblh.fiocruz.br

24. Battaglia FC, Lubhenco LO. A Practical Classification of Newborn Infants by Weight and Gestational Age. J Pediatr. 1967;71(2):159-63.

25. NEPA - Núcleo de Estudos e Pesquisas em Alimentação. Tabela brasileira de composição 
de alimentos. 4a edição. NEPA - Unicamp. Campinas; 2011. 161 p.

26. Philippi ST. Tabela de composição de alimentos - Suporte para decisão nutricional. $5^{\mathrm{a}}$ ed. São Paulo: Manole; 2016. 152p.

27. Pinheiro ABV, Lacerda, Elisa Maria de Aquino Benzecry EH, Gomes MC, Costa VM. Tabela para avaliação de consumo alimentar em medidas caseiras. $5^{a}$ ed. São Paulo: Atheneu; 2005.

28. Pacheco M. Tabela de Equivalentes, Medidas Caseiras e Composição Quimica dos Alimentos. 2a ed. Rio de Jjaneiro: Rúbio; 2011.

29. TBCA USP. Tabela Brasileira de Composição de Alimentos (TBCA). Universidade Federal de São Paulo (USP). Food Research Center (FoRC). Versão 7.0. São Paulo; 2019.

30. Willett W. Implications of total energy intake for epidemiologic analyses. In: Nutritional Epidemiology. 3rd ed. New York: Oxford University Press; 2013. p. 260-286p.

31. World Health Organization (WHO). Physical Status: The Use and Interpretation of Anthropometry. Geneva; 1995.

32. World Health Organization. Obesity: Preventing and managing the global epidemic report of a WHO consultation. 1998;268.

33. IOM (The Institute of Medicine) and NRC (National Research Council). Weight Gain During Pregnancy: Reexamining the Guidelines. Rasmussen KM, Yaktine AL, editors. Washington DC: National Academies Press; 2009. 854 p.

34. Guedes DP. Procedimentos clínicos utilizados para análise da composição corporal. Rev Bras Cineantropometria e Desempenho Hum. 2013;15(1):113-29.

35. Lohman T, editor. Assessing Fat Distribuition. Human Kine. Champaign; 1992.

36. Freitas BAC De, Santos ET, editors. Laboratório de Habilidades na Saúde da Mulher, da Criança e do Adolescente, volume 2, Pediatria. Viçosa: Editora UFV; 2016. 102 p.

37. World Health Organization (WHO). Child Growth Standards. 2006. 
38. World Health Organization (WHO). WHO AnthroPlus for personal computers Manual: Software for assessing growth of the world's children and adolescents. Geneva:WHO. 2009.

39. Training course on child growth assessment. Geneva: World Health Organization. 2008.

40. Carl, B. and Edward R. A. Tiedz Textbook of Clinical Chemistry. 2nd ed. 1994. 1002$1082 \mathrm{p}$

41. Friedewald W, Levy R, Fredrickson D. Estimation of the concentration of low-density lipoprotein cholesterol in plasma, without use of the preparative ultracentrifuge. Clin Chem. 1972;18:499-502.

42. Vallada EP. Manual de Técnicas Hematológicas. Atheneu, editor. São Paulo; 1999. 423p.

43. Stará V, Kopanica M. Cathodic stripping voltammetry and adsorptive stripping voltammetry of selenium(IV). Anal Chim Acta [Internet]. 1988;208:231-6. Available from: https://linkinghub.elsevier.com/retrieve/pii/S0003267000807503

44. Carl A. Burtis, Edward R. Ashwood, and David E. Bruns. Tietz Textbook of Clinical Chemistry and Molecular Diagnostics [Internet]. Fourth Edi. Sauders/Elsevier, editor. St Louis; 2006. 2053-2095 p. Available from: http://www.clinchem.org/cgi/doi/10.1373/clinchem.2005.062638

45. AOAC - Association of Official Analytical Chemistis. 20th Ed. 2016.

46. Instituto Adolfo Lutz. $1^{\text {a }}$ Edição Digital. Métodos físicos-quimicos para análise Aliment. 2008;

47. Bradford MM. A Rapid and Sensitive Method for the Quantitation of Microgram Qauntities of Protein Utilizing the Principle of Protein-Dye Binding. Anal Biochem. $1976 ; 72: 248-54$

48. Rede Brasileira de Bancos de Leite Humano [Internet]. Available from: http://www.redeblh.fiocruz.br/cgi/cgilua.exe/sys/start.htm?infoid=366\&sid=238 
49. Almeida JAG de, Guimarães V, Novak FR. Seleção e Classificação do Leite Humano Ordenado Cru [Internet]. Rio de Janeiro: Rede Nacional de Bancos de Leite Humano; 2005. 5p. Available from: WWW.redeblh.fiocruz.br

50. Ministério da Agricultura A e A. Métodos Analíticos Oficiais Físico-Químicos - Produtos Lácteos. Norma 68. 2006.

51. Martínez B, Miranda JM, Franco CM, Cepeda A, Rodríguez JL. Development of a simple method for the quantitative determination of fatty acids in milk with special emphasis on long-chain fatty acids. CYTA - J Food. 2012;10(1):27-35.

52. The Institute of Medicine of the National Academics. Dietary Reference Intakes: the essential guide to nutrient requirements. Otten JJ, Hellwig JP, Meyers LD, editors. Washington DC: The National Academy Press; 2006.

53. Brasil. Resolução RDC no 12, de 2 de janeiro de 2001. Aprova o "Regulamento técnico sobre padrões microbiológicos para alimentos”. [Internet]. Órgão emissor: ANVISA Agência Nacional de Vigilância Sanitária; Available from: www.anvisa.gov.br

54. Vanderzant C, Splittstoesser DF. Compendium of methods for the microbiological examination of foods. 3 ed. Washington: American Public Health Association; 1992. 1219 p.

55. Yamamoto RM, Campos-Júnior D. Manual Pratico de Atendimento em Consultorio e Ambulatorio de Pediatria. Soc Bras Pediatr. 2006;1(4):58-61. 
Figures
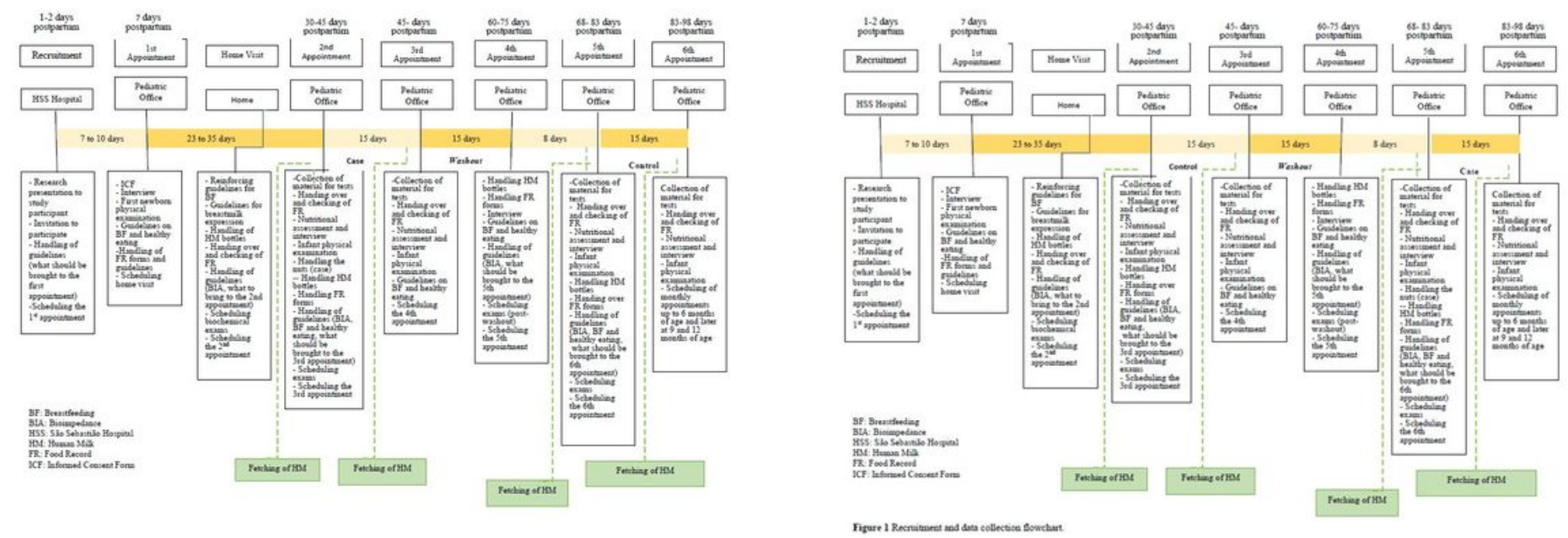

Figure 1

Recruitment and data collection flowchart. 


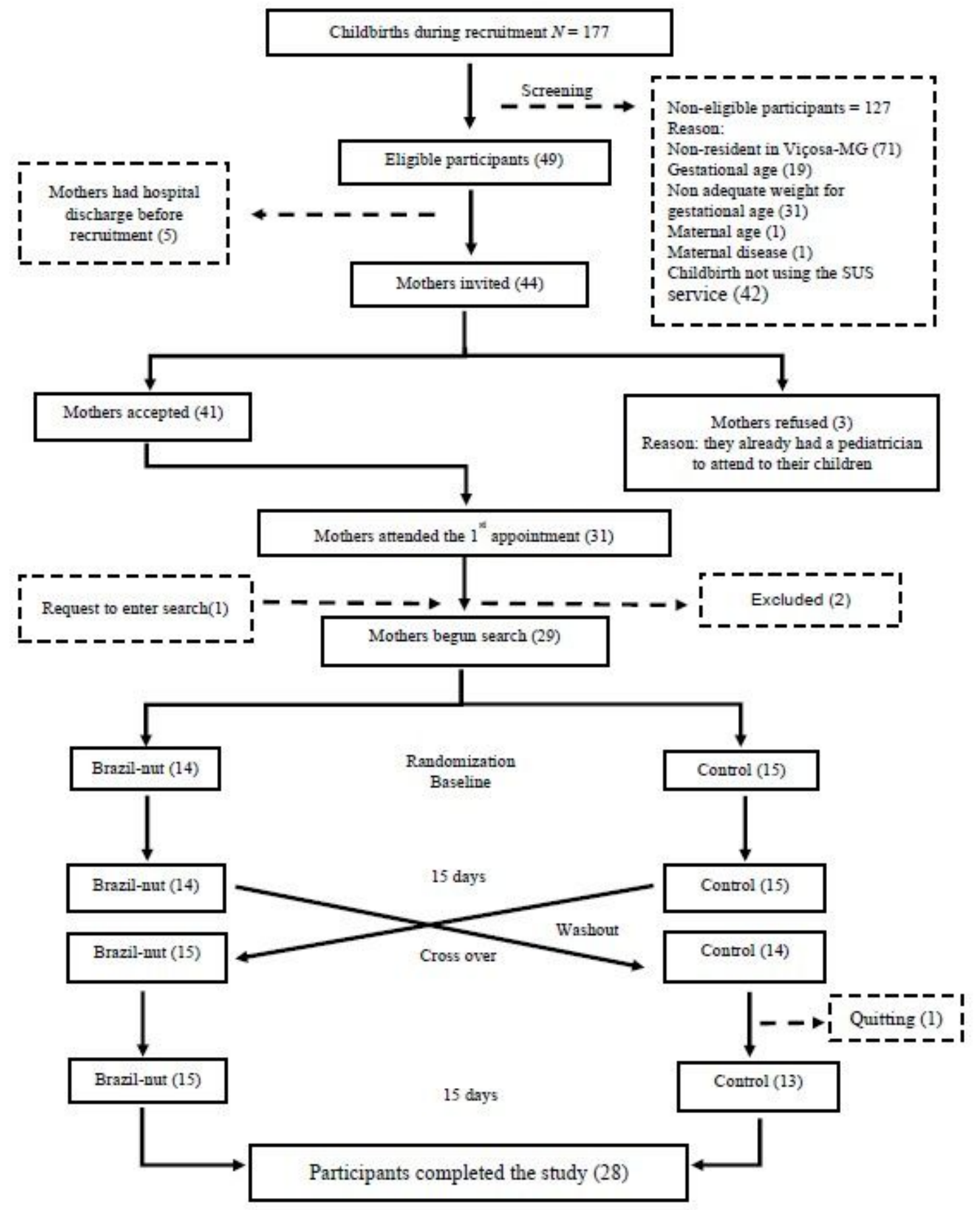

Figure 2

Consort diagram of subjects selected, invited, and who completed the study. 


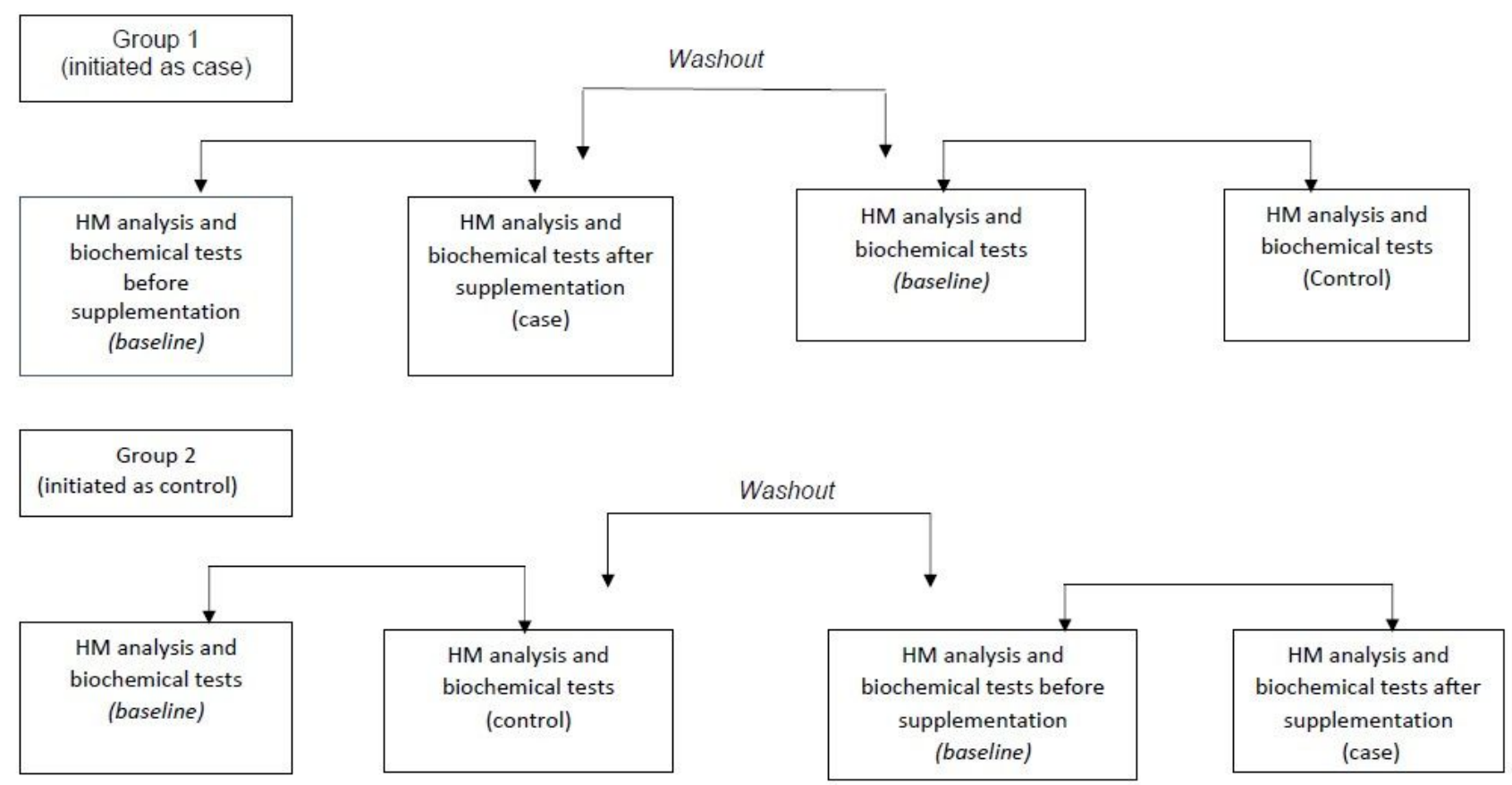

\section{Figure 3}

HM analysis and biochemical tests flowchart.

\section{Supplementary Files}

This is a list of supplementary files associated with this preprint. Click to download.

- AP6GuidelinesforthecollectionofHM.pdf

- AP7CollectionControlTable.pdf

- AP4GuidelinesforCompletingFoodRecords.pdf

- AP3FoodRecordForm.docx.pdf

- Table10utcomemeasures.pdf

- AP1ResearchSampleRecruitmentTable.pdf

- AP5BrazilNutAnalysisQuestionnaireGuidelines.pdf

- Table2BiochMethods.pdf

- AP8InformedConsent.pdf

- AP2ResearchProtocol.pdf 